\title{
Họp đánh giá tiến độ dự án “Phát triển CSDL toán học Việt Nam” tại Viện Nghiên cứu cao cấp về Toán
}

\author{
9/17/2020 7:22 PM
}

$+$

Trung tâm ISR / Trường ĐH Phenikaa (17-09-2020; Tác giả: Nguyễn Thanh Thanh Huyền) - Ngày 16-9-2020 vừa qua, các đại diện của Trung tâm ISR, trường Đại học Phenikaa đã có buổi họp với Viện Nghiên cứu cao cấp về Toán (VIASM), bao gồm GS. TSKH. Ngô Bảo Châu - Giám đốc khoa học, PGS. TS. Lê Minh Hà - Giám đốc điều hành, TS. Trịnh Thị Thúy Giang - Phó Giám đốc về tiến độ dự án "Phát triển cơ sở dữ liệu khoa học ngành toán của Việt Nam".

Dự án là sáng kiến trực tiếp của GS Ngô Bảo Châu, và do Ban lãnh đạo VIASM cùng phối hợp triển khai. Hiện tại, hạ tầng kỹ thuật lưu trữ dữ liệu, phần mềm quản lý, và đội ngũ nhập liệu kiểm soát chất lượng dữ liệu và công tác hosting của dự án do AISDL chịu trách nhiệm đầu tư phát triển. Đồng thời, Trung tâm ISR (thuộc Trường ĐH Phenikaa), do TS Vương Quân Hoàng đại diện, cùng điều phối tổ chức triển khai công việc.

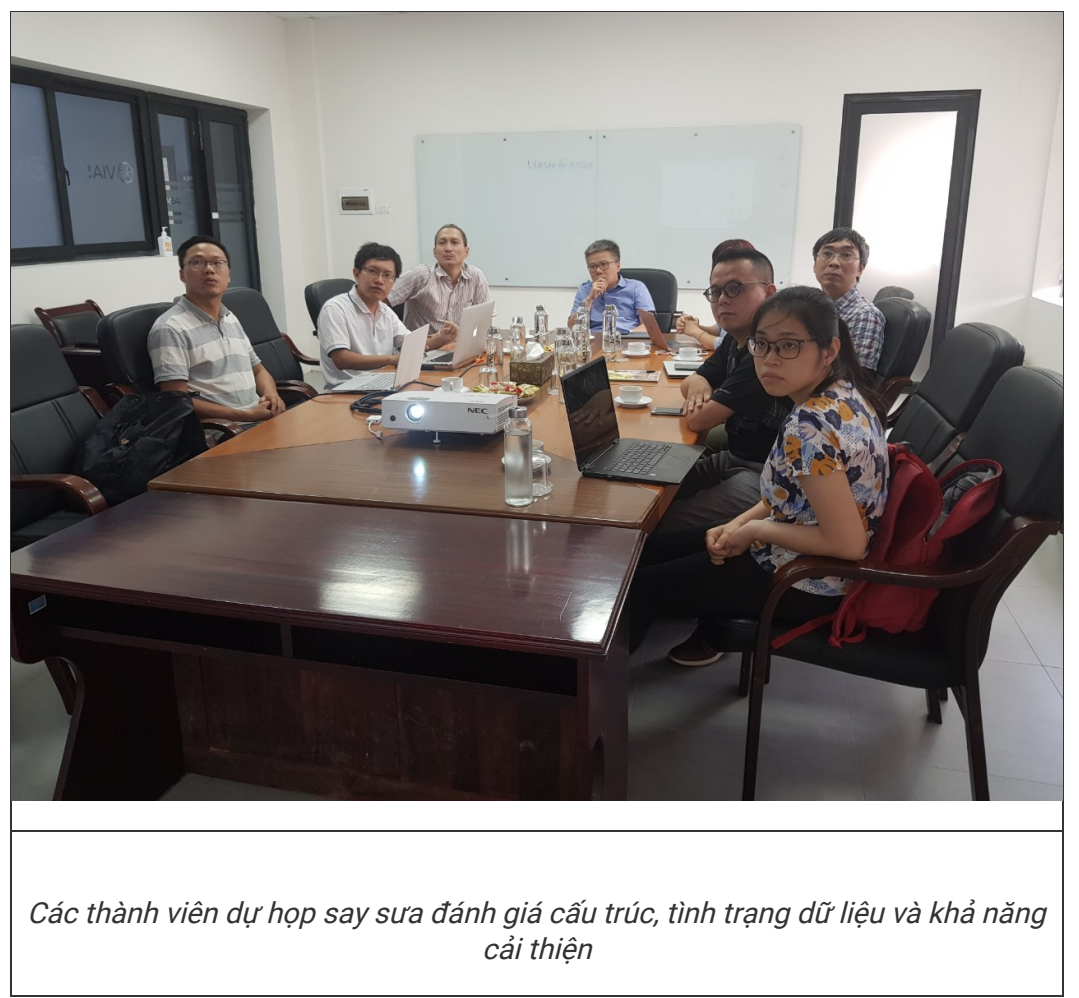

Tại buổi làm việc, đội ngũ xây dựng, cập nhật và chăm sóc cơ sở dữ liệu (CSDL) khoa học ngành toán của Việt Nam đã chia sẻ qua với các lãnh đạo VIASM về cấu trúc CSDL, quá trình tìm kiếm, lọc và nhập liệu, và một số kết quả ban đầu.

Các kết quả rất đáng khích lệ và tạo được sự tin tưởng trong toàn đội ngũ triển khai cũng như BGĐ VIASM.

Ban lãnh đạo VIASM, trong thời gian từ nay tới cuối 2020, sẽ tích cực đôn đốc và bổ sung nguồn lực con người, chuyên gia cho việc hoàn thiện dữ liệu, định hình phân tích và báo cáo, cùng với nhóm dự án AISDL và ISR thúc đẩy các tính năng khai thác, cung cấp thông tin phục vụ xã hội. 


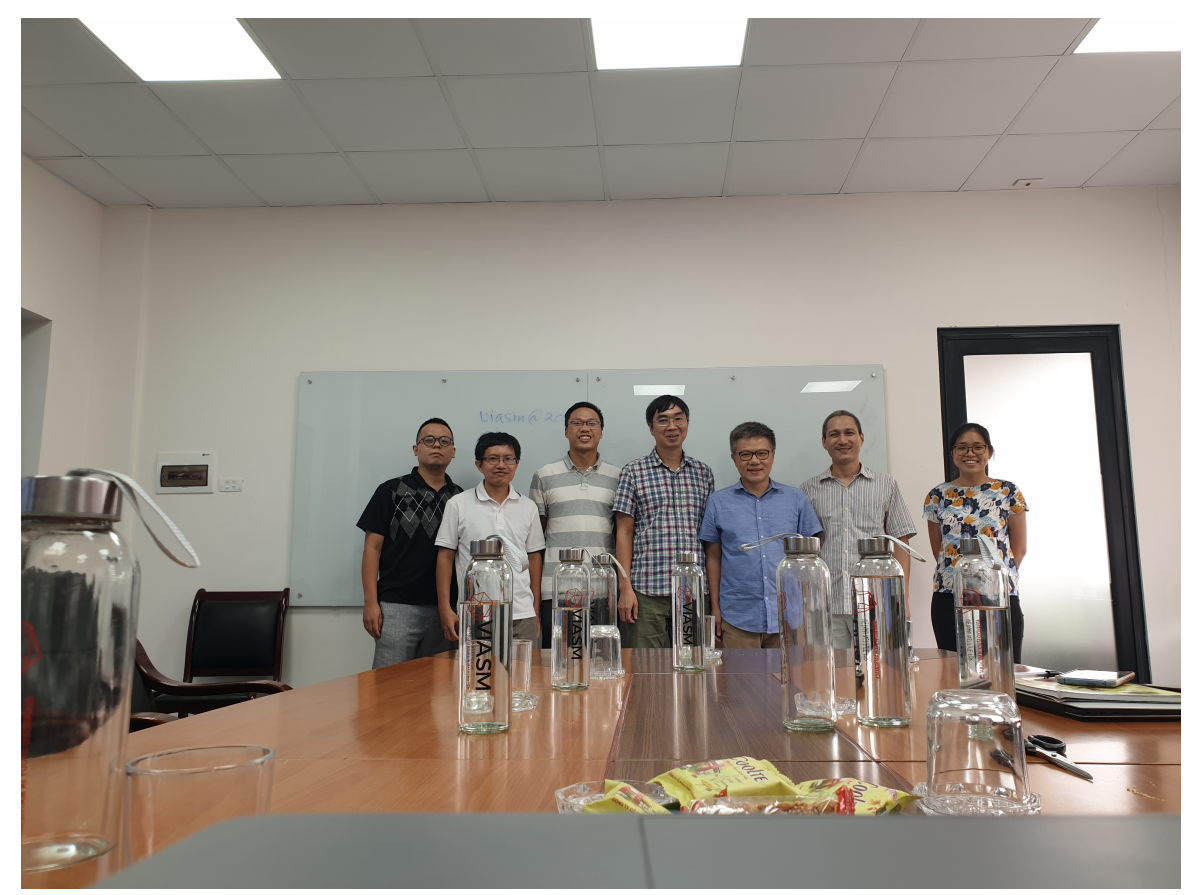

Từ trái qua phải: Phạm Hùng Hiệp (Trung tâm nghiên cứu và phát triển giáo dục Edlab Asia), Lã Việt Phương (ISR), Hồ Mạnh Toàn (ISR), GS. TSKH. Ngô Bảo Châu (Giám đốc khoa học VIASM), Lê Minh Hà (Giám đốc điều hành VIASM), Vương Quân Hoàng (ISR), và Nguyễn Thanh Thanh Huyền (ISR)

Dự án "Phát triển bộ cơ sở dữ liệu khoa học ngành Toán của Việt Nam" được chính thức khởi động vào ngày 02/01/2020. Dựa trên cơ sở là các CSDL khoa học quốc tế như Mathscinet, Zentralblatt MATH, ISI Web of Science hay Scopus, dự án hướng tới xây dựng một CSDL trải dài lịch sử đã gần 80 năm xây dựng và phát triển của nền toán học Việt Nam.

Trong tương lai, bộ dự liệu này sẽ là cơ sở để phát triển các dự án nghiên cứu về năng suất nghiên cứu, lịch sử ngành Toán, xu hướng hợp tác, và các nghiên cứu khác liên quan tới sự phát triển trong tương lai của Toán học tại Việt Nam.

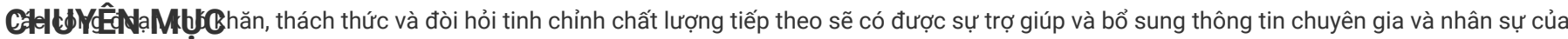

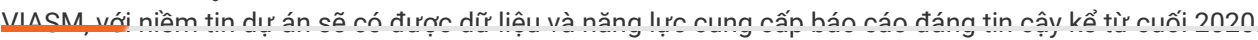

< v Thông báo

Tin tức

Sự kiện

\section{GIớI THIÊEU}

\section{TUYỂN SINH}

ĐớN V! TRỰC THUỘC

\section{TIN TỨC}




\section{HợP TÁC}

LIÊN HÊ

TT NGHIÊN CỨU KHXH LIÊN NGÀNH

• Phường Yên Nghĩa - Quận Hà Đông - Hà Nội

C $\underline{0242.2180 .336}$ | Hotline: 094.651 .1010

$\square$ Info@phenikaa.edu.vn

c www.phenikaa.edu.vn

\section{f) $8^{*} \otimes 0$}

